Supporting information

\title{
Crown-ether Derived Graphene Hybrid Composite for Membrane-Free Potentiometric Sensing of Alkali Metal Ions
}

\author{
Gunnar Olsen, Jens Ulstrup and Qijin Chi* \\ Department of Chemistry, Technical University of Denmark, \\ DK-2800 Kongens Lyngby, Denmark.
}

(*Corresponding author. E-mail: cq@kemi.dtu.dk; Phone: +4545252032;

Fax: +45 45883136) 


\section{Contents}

\section{S1. Experimental details of synthesis}

Synthesis of graphene oxide by modified Hummers method..............................................................

Preparation of $\mathrm{N}$-tert-Butyloxycarbonyl- $\mathrm{N}$-2-aminoacetate-1-aza-18-crown[6] ether ...........................S-4

Preparation of $\mathrm{N}$-2-aminoacetate-1-aza-18-crown[6] ether .................................................................

Functionalization and subsequent reduction of GO to prepare RGO-crown[6] .................................. -5

S2. AFM images

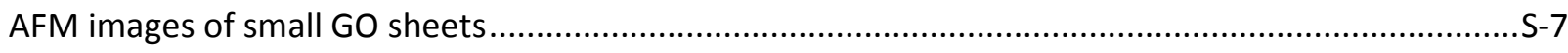

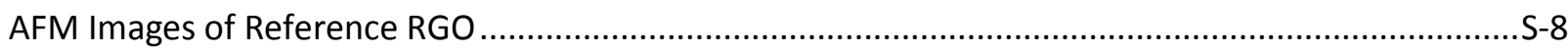

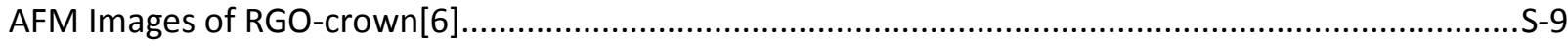

S3. FT-IR Data

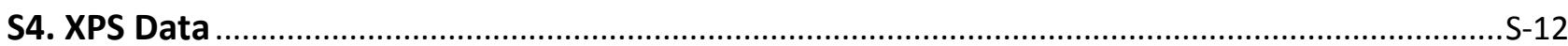

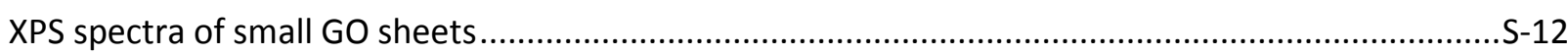

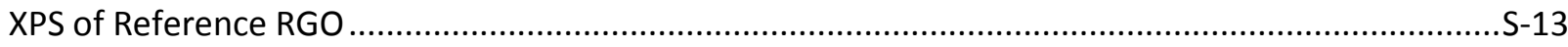

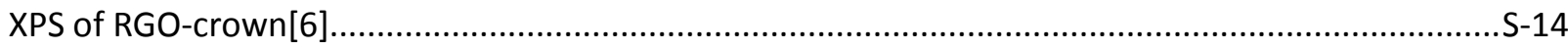

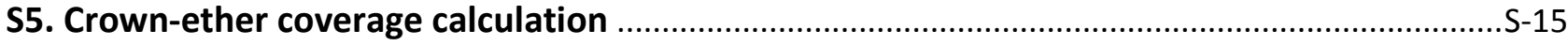

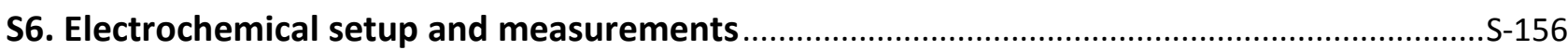

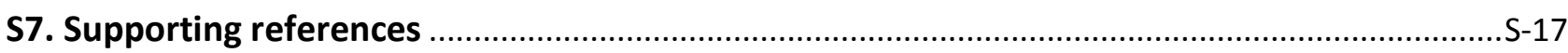




\section{S1. Experimental details of synthesis}

All chemicals were from Sigma-Aldrich or Fluka and used as received. $\mathrm{CH}_{2} \mathrm{Cl}_{2}$ was distilled immediately prior to use, anhydrous THF was dried on a PureSolv purification system. Milli-Q water was used throughout $(18.2 \mathrm{M} \Omega \mathrm{cm})$. Analytical thin-layer chromatography (TLC) was performed using alumina sheets pre-coated with silica gel 60F (Merck 5554), which were inspected by UV-light ( $254 \mathrm{~nm}$ ) prior to development with alkaline $\mathrm{KMnO}_{4}$ and heat gun. $1 \mathrm{D}$ and $2 \mathrm{D} \mathrm{NMR}$ spectra were recorded on a Bruker AVANCE III $400 \mathrm{MHz}$ Spectrometer, where ${ }^{1} \mathrm{H}-\mathrm{NMR}$ was recorded at $400 \mathrm{MHz}$ at $298 \mathrm{~K}$, and ${ }^{13} \mathrm{C}-\mathrm{NMR}$ at $100 \mathrm{MHz}$ at $298 \mathrm{~K}$. The NMR samples were dissolved in $\mathrm{CDCl}_{3} 99.8 \% \mathrm{D}$ from Sigma-Aldrich, and tetramethylsilane or the residual solvent were used as internal standard. Solvent signals were assigned according to Fulmer et. al. ${ }^{1}$. IR spectra were recorded on a Bruker ALPHA FT-IR spectrometer. An Eppendorf Centrifuge 5810R V8.4 was used for all centrifugations

\section{Synthesis of graphene oxide by modified Hummers method}

Graphene oxide (GO) was prepared in two steps. Pre-oxidized graphite was prepared in the first step, and GO from pre-oxidized graphite in the second step.

Graphite Flakes (powder, < $20 \mu \mathrm{m}$, synthetic) $\left(5.0 \mathrm{~g}\right.$ ) was added to $15 \mathrm{~mL} \mathrm{H}_{2} \mathrm{SO}_{4}$ (96\%) solution containing $\mathrm{K}_{2} \mathrm{~S}_{2} \mathrm{O}_{8}(2.5 \mathrm{~g})$ and $\mathrm{P}_{2} \mathrm{O}_{5}(2.5 \mathrm{~g})$ at $80{ }^{\circ} \mathrm{C}$. After $3 \mathrm{~h}$ the reaction was cooled to RT and the dark blue mixture diluted with $30 \mathrm{~mL}$ Milli-Q water. The diluted reaction mixture was filtered and washed with Milli-Q water until the waste solution reached neutral $\mathrm{pH}$. The resulting pre-oxidized graphite powder was dried in vacuo.

Pre-oxidized graphite (1.1 g) was added to $25 \mathrm{~mL} \mathrm{H}_{2} \mathrm{SO}_{4}(96 \%)$ in an ice-water bath $\left(0^{\circ} \mathrm{C}\right) . \mathrm{KMnO}_{4}(3.2 \mathrm{~g})$ was then added slowly $(20 \mathrm{~min})$ under stirring, so that the temperature of the solution was maintained between $0-20{ }^{\circ} \mathrm{C}$ during the addition. After addition the reaction mixture was stirred at $35{ }^{\circ} \mathrm{C}$ for $2 \mathrm{~h}$. The reaction was terminated by addition of $140 \mathrm{~mL}$ Milli-Q water and $0.5 \mathrm{~mL} \mathrm{H} \mathrm{O}_{2}(30 \% \mathrm{aq})$. The solution was centrifuged (12000 RPM, $18192 \mathrm{~g}$ ) to remove the aqueous phase and then washed by repeated centrifugation (12000 RPM, $18192 \mathrm{~g}$ ) with $5 \times 180 \mathrm{~mL} \mathrm{HCl}$ $(10 \%$ aq) and $5 \times 180 \mathrm{~mL}$ Milli-Q water retaining the solid $\mathrm{GO}$ and discarding 
aqueous phase. After washing, the sedimented GO was redispersed in Milli-Q water and divided into approximate size distributions using centrifugation.

The dispersion was first centrifuged at low speed (1000 RPM, $126 \mathrm{~g}$ ). The sediment from this step was discarded as Graphitic GO. The supernatant was then centrifuged at medium speed (4000 RPM, $2021 \mathrm{~g}$ ). This sediment was redispersed and centrifuged at low speed (1000 RPM, $126 \mathrm{~g}$ ). This supernatant was marked as large GO sheets (mostly 10-20 $\mu \mathrm{m}$ ). The supernatant from medium speed centrifugation was centrifuged again at medium-high speed (8000 RPM, $8085 \mathrm{~g}$ ) and the sediment was redispersed and centrifuged at medium speed (4000 RPM, 2021 g). This supernatant was marked as medium GO sheets (mostly 5-15 $\mu \mathrm{m}$ ). The supernatant from medium-high speed centrifugation was then centrifuged at high speed (12000 RPM, $18192 \mathrm{~g}$ ) and the sediment from this step redispersed and centrifuged at medium-high speed (8000 RPM, 8085 g). This supernatant was marked as small GO sheets (mostly 1-8 $\mu \mathrm{m}$ ). The supernatant from the high-speed centrifugation was kept as very small and fragmented GO sheets (mostly $<1 \mu \mathrm{m}$ ) and also contains GO nanoparticles. The size of the GO sheets determined by AFM images also showed sheets of other sizes in all four size-distributions but most of the sheets are within the size distribution given.

After size separation the GO sheets were purified by dialysis over a week $(27 \times 1 \mathrm{~L}$ Milli-Q water) using Spectra/Por membrane MWCO 12000 - 14 000. Dialysis water was changed 5 times daily during the first five days but only once daily over the final two days. After dialysis the concentration was determined by drying $5 \mathrm{~mL}$ of the solution in vacuum and weighing the residual powder.

Small GO sheets were used in all further experiments in this work.

\section{Preparation of $N$-tert-Butyloxycarbonyl- $N$-2-aminoacetate-1-aza-18- crown[6]ether}

Boc-glycin (189.8 mg; $1.08 \mathrm{mmol}$ ) and Triphosgene (98.6 mg; $0.37 \mathrm{mmol}$ ) were dissolved in anhydrous THF (12 mL) followed by dropwise addition of lutidine $(0.7 \mathrm{~mL})$ under vigorous reaction. After addition this mixture was slowly added to a heated solution of 1-aza-18-crown[6]ether ( $60.5 \mathrm{mg} ; 0.23 \mathrm{mmol}$ ) dissolved in anhydrous THF (15 
$\mathrm{mL}$ ) at $50^{\circ} \mathrm{C}$. After $2 \mathrm{~h}$ the reaction was stopped by addition of $20 \mathrm{~mL}$ Milli-Q water and $30 \mathrm{~mL} \mathrm{HCl}(1 \mathrm{M}, \mathrm{aq})$ and immediately extracted with $\mathrm{CH}_{2} \mathrm{Cl}_{2}(3 \times 30 \mathrm{~mL})$. The organic phase was washed with $\mathrm{NaOH}_{(1 \mathrm{M}, \text { aq) }}(20 \mathrm{~mL}), \mathrm{H}_{2} \mathrm{O}(20 \mathrm{~mL})$, and dried over $\mathrm{Na}_{2} \mathrm{SO}_{4}(\mathrm{~s})$. The solvent was removed in vacuo to a slightly yellow oil $(92.5 \mathrm{mg}, 0.22 \mathrm{mmol}, 95 \%)$ which was dried overnight in vacuo.

$\operatorname{TLC}\left(\mathrm{CH}_{2} \mathrm{Cl}_{2}\right.$ 9:1 MeOH): $\mathrm{R}_{\mathrm{f}}=0.34-0.38$

1H-NMR (400 MHz, CDCl, $298 \mathrm{~K}) \delta: 5.48\left(\mathrm{~S}, 2 \mathrm{H}, \mathrm{N}(\mathrm{CO}) \mathrm{CH}_{2} \mathrm{~N}(\mathrm{CO})\right), 4.01$ (d, J = 4.6 Hz, 4H, $\left.\left(\mathrm{CH}_{2}\right)_{2} \mathrm{~N}(\mathrm{CO}) \mathrm{R}\right)$

$3.73-3.50\left(\mathrm{~m}, 2 \mathrm{OH}, \mathrm{CH}_{2} \mathrm{CH}_{2} \mathrm{O}\right), 1.41\left(\mathrm{~s}, 9 \mathrm{H}, \mathrm{OC}\left(\mathrm{CH}_{3}\right)_{3}\right)$.

${ }^{13} \mathrm{C}-\mathrm{NMR}\left(101 \mathrm{MHz}, \mathrm{CDCl}_{3}\right)$ 8: $167.79\left(\mathrm{R}_{2} \mathrm{~N}(\mathrm{CO}) \mathrm{R}\right), 154.76(\mathrm{~N}(\mathrm{CO}) \mathrm{O}), 78.35\left(\mathrm{OC}\left(\mathrm{CH}_{3}\right)_{3}\right)$, $70.03,69.77,69.70,69.67,69.64,69.56,69.53,69.33,68.52,68.31\left(10 \times \mathrm{OCH}_{2} \mathrm{CH}_{2}\right), 47.11$, $45.84\left(2 \times \mathrm{NCH}_{2} \mathrm{CH}_{2}\right), 41.31\left(\mathrm{~N}(\mathrm{CO}) \mathrm{CH}_{2} \mathrm{NCO}\right), 27.37\left(\mathrm{OC}\left(\mathrm{CH}_{3}\right)_{3}\right)$.

\section{Preparation of $\mathrm{N}$-2-aminoacetate-1-aza-18-crown[6]ether}

$\mathrm{N}$-tert-Butyloxycarbonyl-N-2-aminoacetate-1-aza-18-crown[6]ether $(92 \mathrm{mg}, 0.22$ mmol) was dissolved in $20 \mathrm{~mL} \mathrm{CH} \mathrm{Cl}_{2}, 10 \mathrm{~mL}$ trifluoroacetic acid added, and stirred at RT for $1 \mathrm{~h}$. The reaction mixture was concentrated to oil in vacuo. The oil was redissolved in $\mathrm{CH}_{2} \mathrm{Cl}_{2}(20 \mathrm{~mL})$, washed with $\mathrm{NaOH}\left(1 \mathrm{M}\right.$ aq) $(2 \times 20 \mathrm{~mL}), \mathrm{H}_{2} \mathrm{O}(20 \mathrm{~mL})$, and dried over $\mathrm{Na}_{2} \mathrm{SO}_{4}$ (s). Solvent was removed to give a slightly yellow oil (59 mg, $0.18 \mathrm{mmol}, 84 \%)$ which was dried overnight in vacuo.

$\operatorname{TLC}\left(\mathrm{CH}_{2} \mathrm{Cl}_{2}\right.$ 9:1 MeOH): $\mathrm{R}_{\mathrm{f}}=0.06-0.09$

1H-NMR (400 MHz, CDCl $3,298 \mathrm{~K}) \delta: 3.98\left(\mathrm{bs}, 4 \mathrm{H},\left(\mathrm{CH}_{2}\right)_{2} \mathrm{~N}(\mathrm{CO}) \mathrm{R}\right) 3.71-3.61(\mathrm{~m}, 2 \mathrm{H}$, $\left.\mathrm{CH}_{2} \mathrm{CH}_{2} \mathrm{O}\right), 2.72\left(\mathrm{~s}, 2 \mathrm{H}, \mathrm{N}(\mathrm{CO}) \mathrm{CH}_{2} \mathrm{NH}_{2}\right)$. ( $\mathrm{No} \mathrm{NH}_{2}$ signal was observed as the protons are too labile in the NMR time scale.)

${ }^{13} \mathrm{C}-\mathrm{NMR}\left(101 \mathrm{MHz}, \mathrm{CDCl}_{3}\right)$ ): $159.80\left(\mathrm{R}_{2} \mathrm{~N}(\mathrm{CO}) \mathrm{R}\right), 70.73,70.69,70.68,69.84,69.57$, $69.45,69.19,69.17,69.14,69.10\left(10 \times \mathrm{OCH}_{2} \mathrm{CH}_{2}\right), 29.48,49.43\left(2 \times \mathrm{NCH}_{2} \mathrm{CH}_{2}\right), 40.94$ $\left(\mathrm{NCOCH}_{2} \mathrm{NH} 2\right)$.

\section{Functionalization and subsequent reduction of GO to prepare RGO-crown[6]}

High concentration of small graphene oxide sheet dispersion with a total GO mass of $10 \mathrm{mg}$ was diluted to $10 \mathrm{~mL}$ for a final concentration of $1 \mathrm{mg} / \mathrm{mL}$. N-2aminoacetate-1-aza-18-crown[6]ether $(16 \mathrm{mg}, 0.05 \mathrm{mmol})$ was then added to the 
solution in a minimum of Milli-Q water $(0.5 \mathrm{~mL})$ and the dispersion stirred vigorously for $30 \mathrm{~min}$. $\mathrm{KOH}(8 \mathrm{M} \mathrm{aq})(0.25 \mathrm{~mL})$ was added for a final concentration of $0.02 \mathrm{M}$, and the reaction mixture was heated to $60^{\circ} \mathrm{C}$ and stirred overnight.

Additional $\mathrm{KOH}(8 \mathrm{M} \mathrm{aq})(1.25 \mathrm{~mL})$ was added to the reaction mixture in the following day and the temperature increased to $80{ }^{\circ} \mathrm{C}$ for 6 hours before cooling to room temperature, centrifuged at (12000 RPM, $18192 \mathrm{~g})$ and washed twice by centrifugation with Milli-Q water $(2 \times 100 \mathrm{~mL})$. After the third centrifugation the sediment was redispersed in $\mathrm{H}_{2} \mathrm{O}(100 \mathrm{~mL})$ and dialyzed over a week $\left(27 \times 1 \mathrm{~L} \mathrm{H}_{2} \mathrm{O}\right)$ using Spectra/Por membranes MWCO 12000 - 14000. 


\section{S2. AFM imaging and analysis of various nanostructures}

All AFM Images were recorded in the contact mode using an Agilent SPS 5500 instrument in open loop setup with an Agilent multipurpose scanner $90 \mu \mathrm{m} \times 90 \mu \mathrm{m}$ equipped with a Bruker DNP-S tip with a force constant of $\approx 0.35 \mathrm{~N} / \mathrm{m}$ and $\approx 10 \mathrm{~nm}$ tip radius. The images were analysed in Pico Image Basic V.6.2 using Picoview V.14.4 as imaging software.

\section{AFM images of "small GO sheets"}
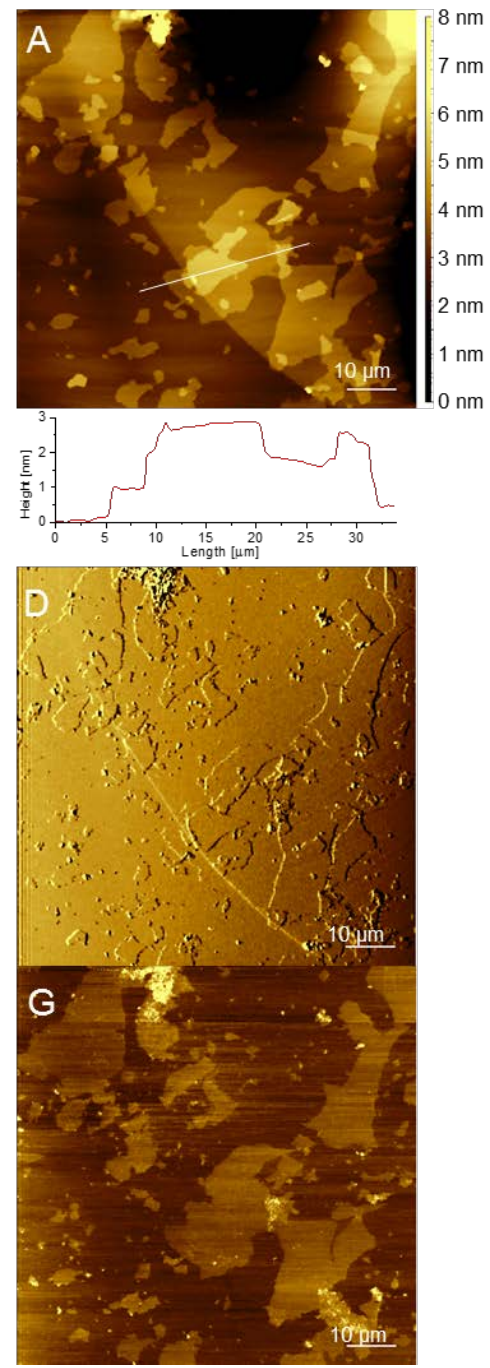
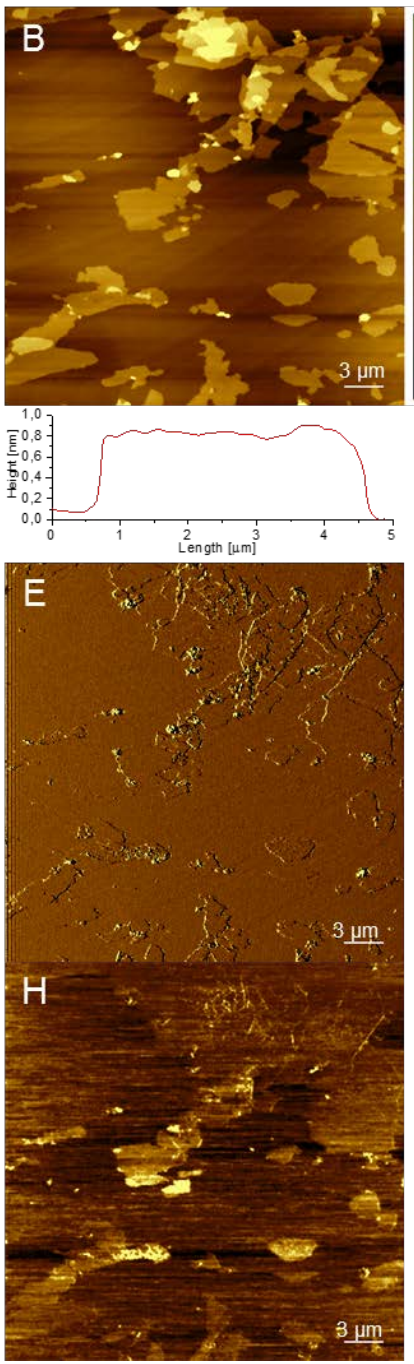
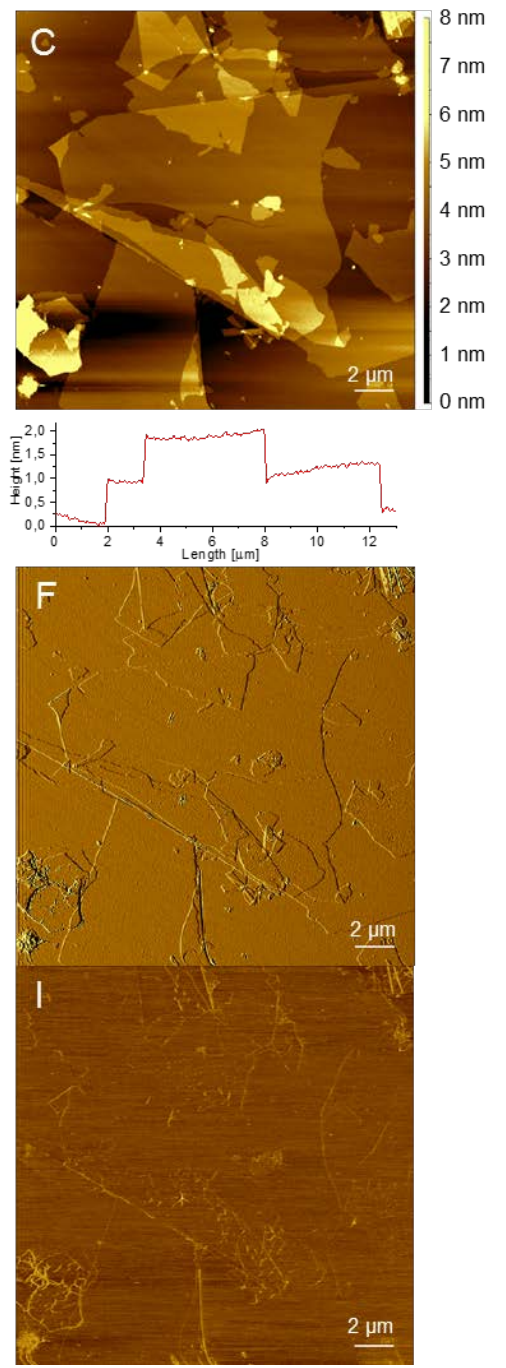

Figure S1. AFM images of GO drop cast on mica showing several single-layer sheets either separate or overlapping in the XY-size range of approximately 1-8 $\mu \mathrm{m}$. Topography of three separate images with height profiles A) $80 \times 80 \mu \mathrm{m} \mathrm{B}$ ) $30 \times 30 \mu \mathrm{m} \mathrm{C)} 20 \times 20 \mu \mathrm{m}$; corresponding deflection images $D$ ), E) and F); and corresponding friction images $G$ ), I) and $H$ ). 


\section{AFM Images of Reference RGO}
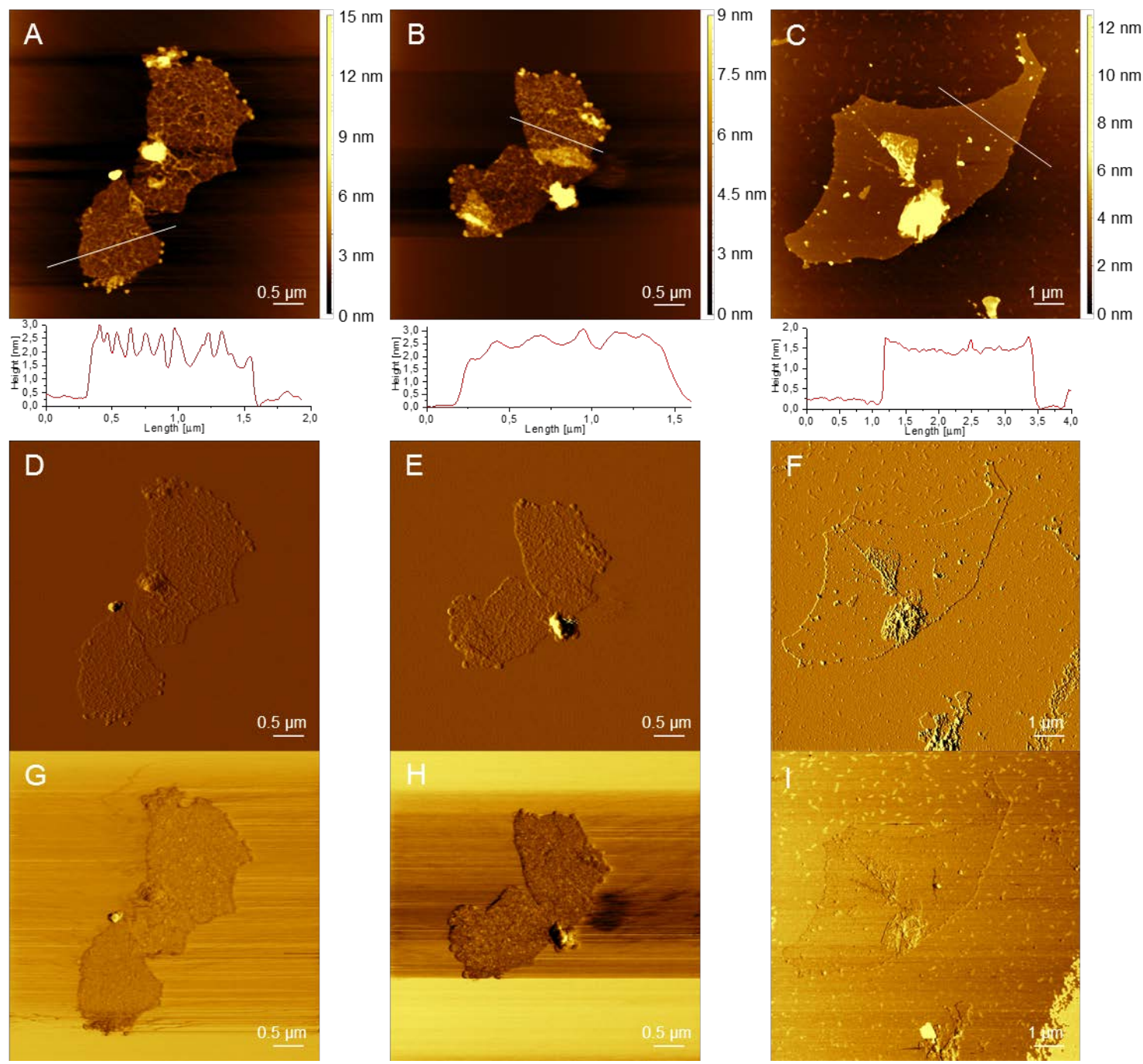

Figure S2. AFM images of RGO drop cast on mica showing single-layer sheet of XY-size range of 1$4 \mu \mathrm{m}$. Topography of three separate images with height profiles A) $5 \times 5 \mu \mathrm{m}$ B) $5 \times 5 \mu \mathrm{m} \mathrm{C}) 10 \times 10$ $\mu \mathrm{m}$; corresponding deflection images D), E) and F); and corresponding friction images G), I) and H). 


\section{AFM Images of RGO-crown[6]}
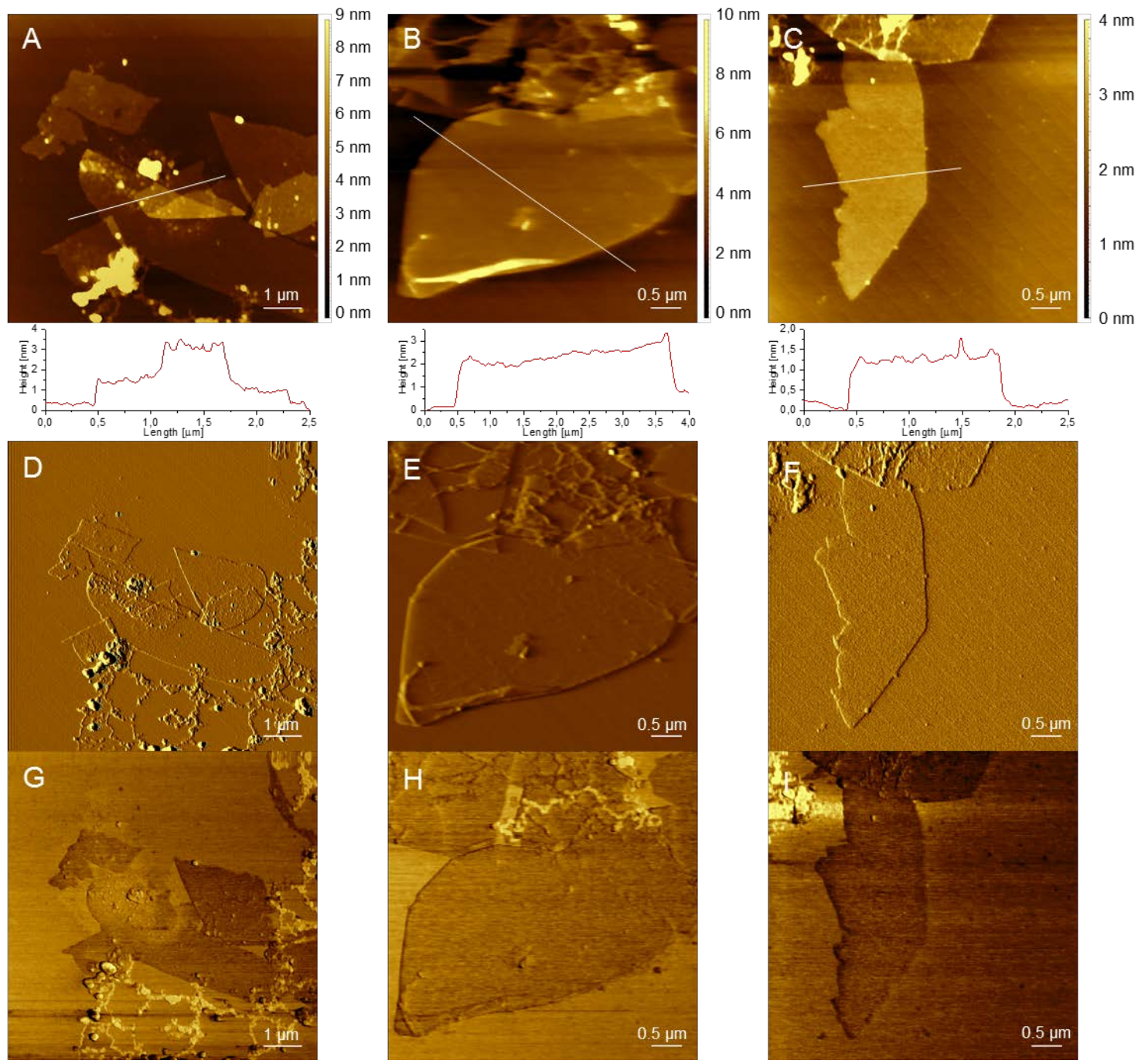

Figure S3. AFM images of RGO-crown[6] drop cast on mica showing single-layer sheet of 1-4 $\mu \mathrm{m}$ XY-size range. Topography of three separate images with height profiles A) $5 \times 5 \mu \mathrm{m}$ B) $5 \times 5 \mu \mathrm{m} \mathrm{C}$ ) $10 \times 10 \mu \mathrm{m}$; corresponding deflection images D), E) and F); and corresponding friction images G), I) and $\mathrm{H})$. 


\section{S3. FT-IR Spectra}

ATR FT-IR spectra were recorded on a Bruker Alpha ATR FT-IR spectrometer on vacuum dried material samples.

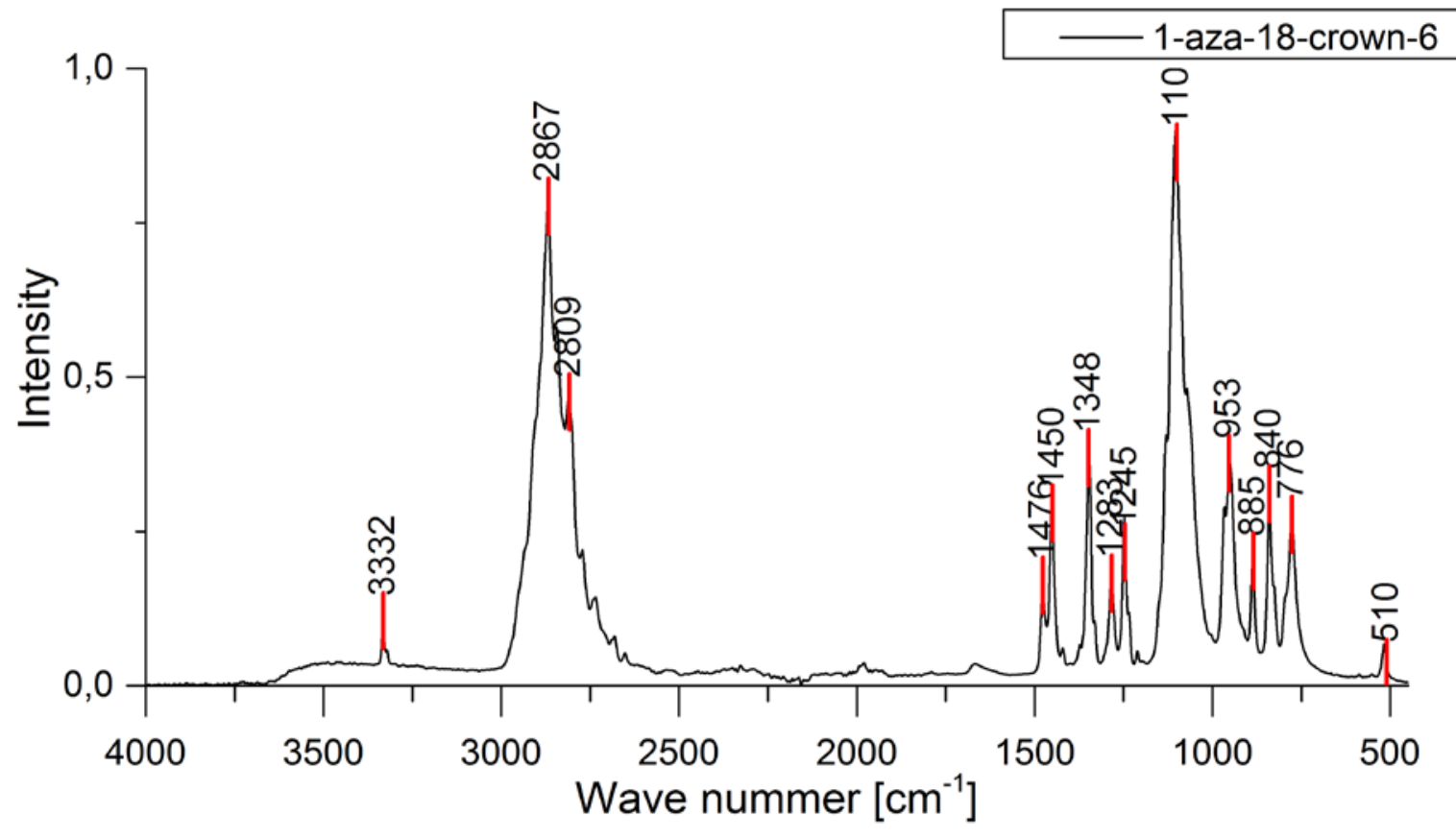

Figure S4. Full ATR-FT-IT spectrum of 1-aza-18-crown[6]ether, showing the main vibrations in the $1500-750 \mathrm{~cm}^{-1}$ region and aliphatic $\mathrm{C}-\mathrm{H}$ stretch $2800 \mathrm{~cm}^{-1}$. The main peak appears at $1100 \mathrm{~cm}^{-1}$.

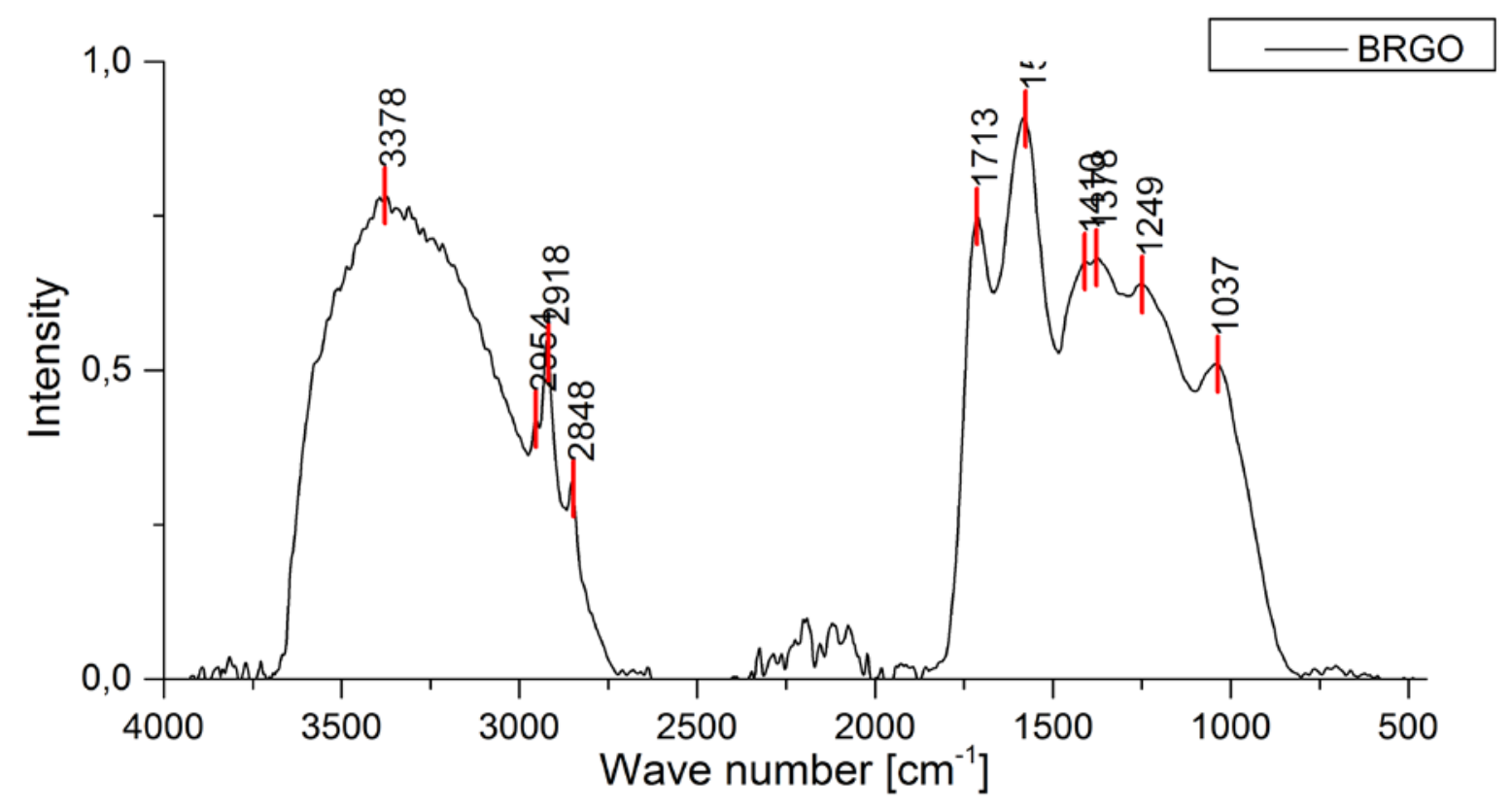

Figure S5. Full ATR-FT-IT spectrum of reference RGO showing main vibrations in the $1750-1000$ $\mathrm{cm}^{-1}$ region. Specific differences between crown ether and RGO is the COO-H stretch at 3600-2700 $\mathrm{cm}^{-1}$ and the $\mathrm{C}=\mathrm{O}$ stretch at $1700 \mathrm{~cm}^{-1}$. 


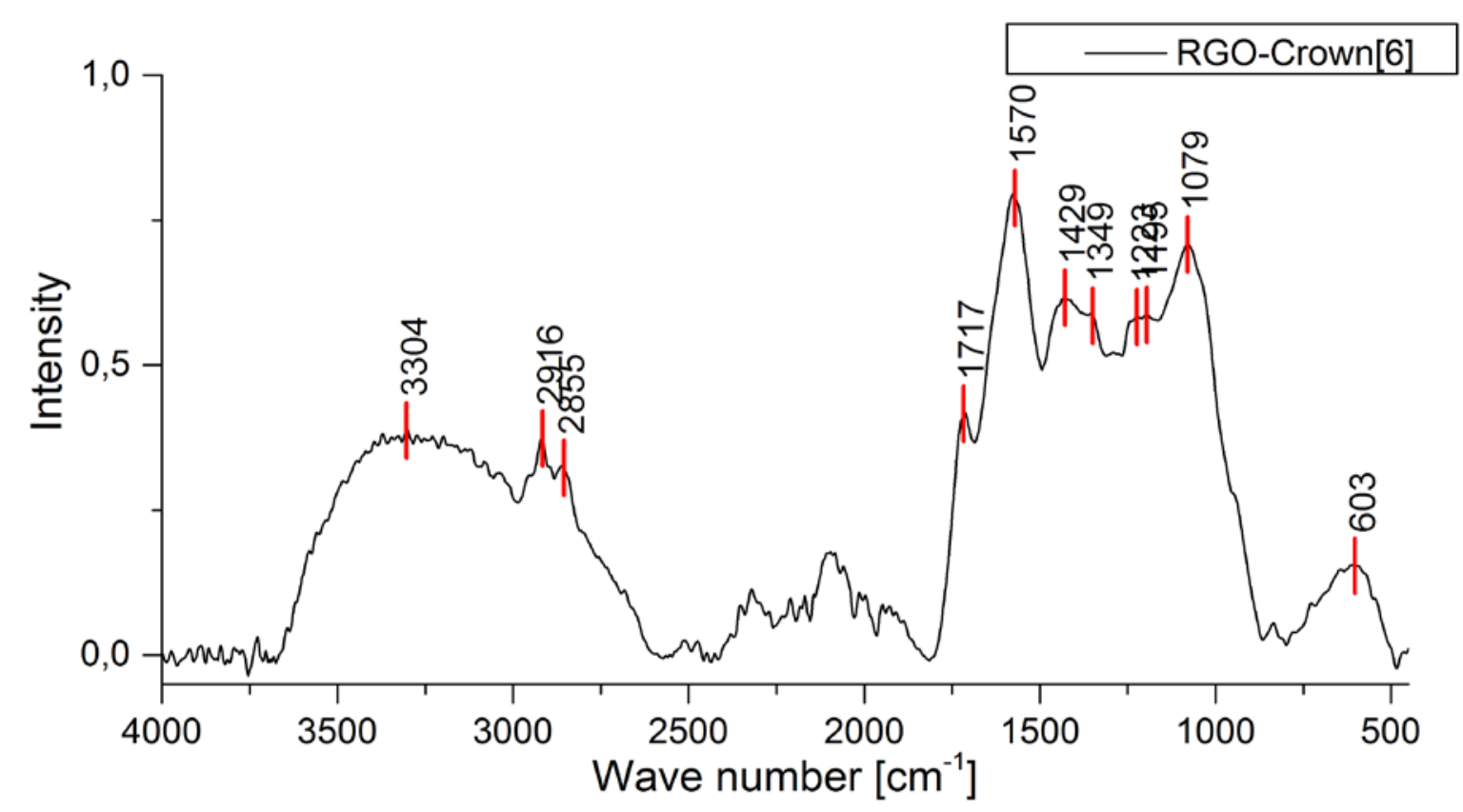

Figure S6. Full ATR-FT-IR spectrum of RGO-crown[6], showing main vibrations in the $1750-750 \mathrm{~cm}$ ${ }^{1}$ region and carboxylic acid COO-H stretch.

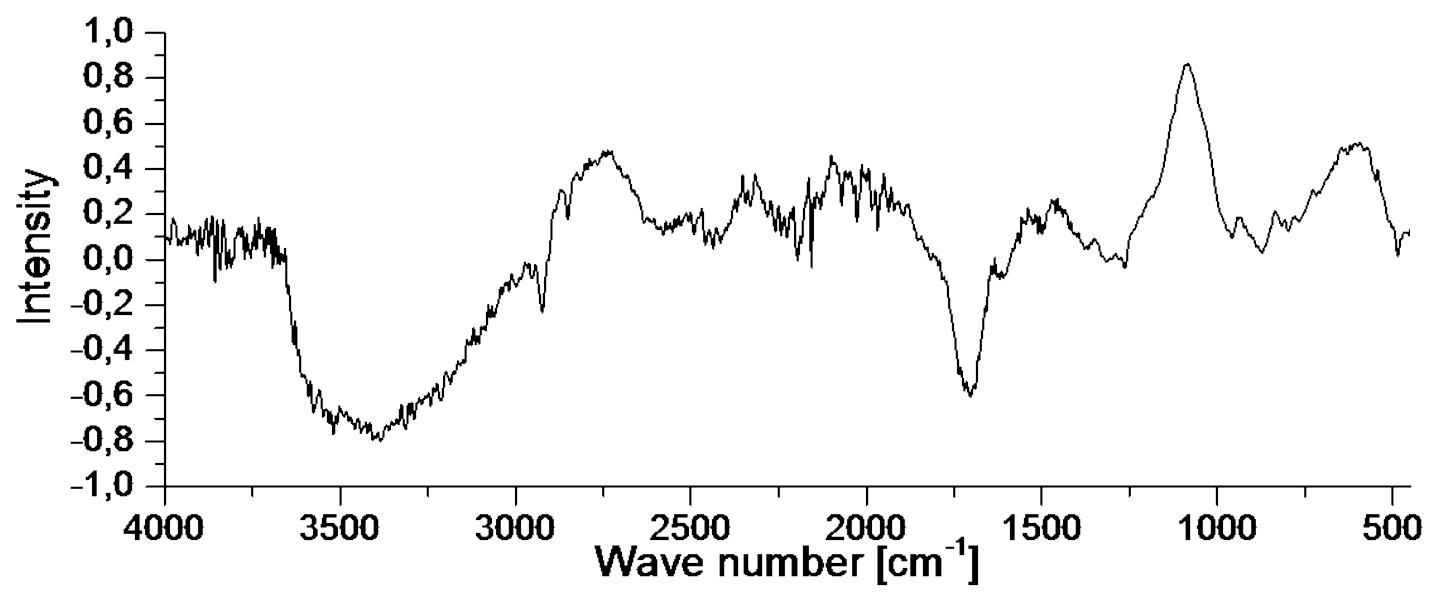

Figure S7. Full differential spectrum of RGO-crown[6] versus reference RGO showing that the main difference in the two spectra is a reduction in carboxylic acid at $3600-2900 \mathrm{~cm}^{-1}$ and $\mathrm{C}=0$ stretch at $1750 \mathrm{~cm}^{-1}$ which is the dominating feature of RGO as well as an increase around 1100 $\mathrm{cm}^{-1}$ which is the main feature of 1-aza-18-crown[6\}ether. 


\section{S4. XPS spectroscopic analysis}

XPS data recorded on Thermo Scientific X-ray photoelectron spectrometer with an Al K-Alpha (1486 eV) x-ray source. All samples were measured by depositing the material on polished Si-wafer by drop casting. In all measurements X-ray spot area is set to $400 \mu \mathrm{m}$ and flood gun used for charge compensation. The following spectra were recorded in all cases:

1) Survey (pass energy $2000 \mathrm{KeV}$, energy step $1 \mathrm{KeV}$, scans 2, dwell time $50 \mathrm{~s}$ )

2) $\mathrm{Si} 2 \mathrm{p}$ (pass energy $50 \mathrm{KeV}$, energy setp $0.1 \mathrm{KeV}$, scans 2, dwell time $50 \mathrm{~s}$ )

3) $\mathrm{S} 2 \mathrm{p}$ (pass energy $50 \mathrm{KeV}$, energy step $0.1 \mathrm{KeV}$, scans 2, dwell time $50 \mathrm{~s}$ )

4) $\mathrm{C} 1 \mathrm{~s}$ (pass energy $50 \mathrm{KeV}$, energy step $0.1 \mathrm{KeV}$, scans 12 , dwell time $50 \mathrm{~s}$

5) $\mathrm{N} 1 \mathrm{~s}$ (pass energy $2000 \mathrm{KeV}$, energy step $0.1 \mathrm{KeV}$, scans 12, dwell time 50

6) $01 \mathrm{~s}$ (pass energy $2000 \mathrm{eV}$, energy step $0.1 \mathrm{KeV}$, scans 6, dwell time 50s)

\section{XPS spectra of "small GO sheets"}
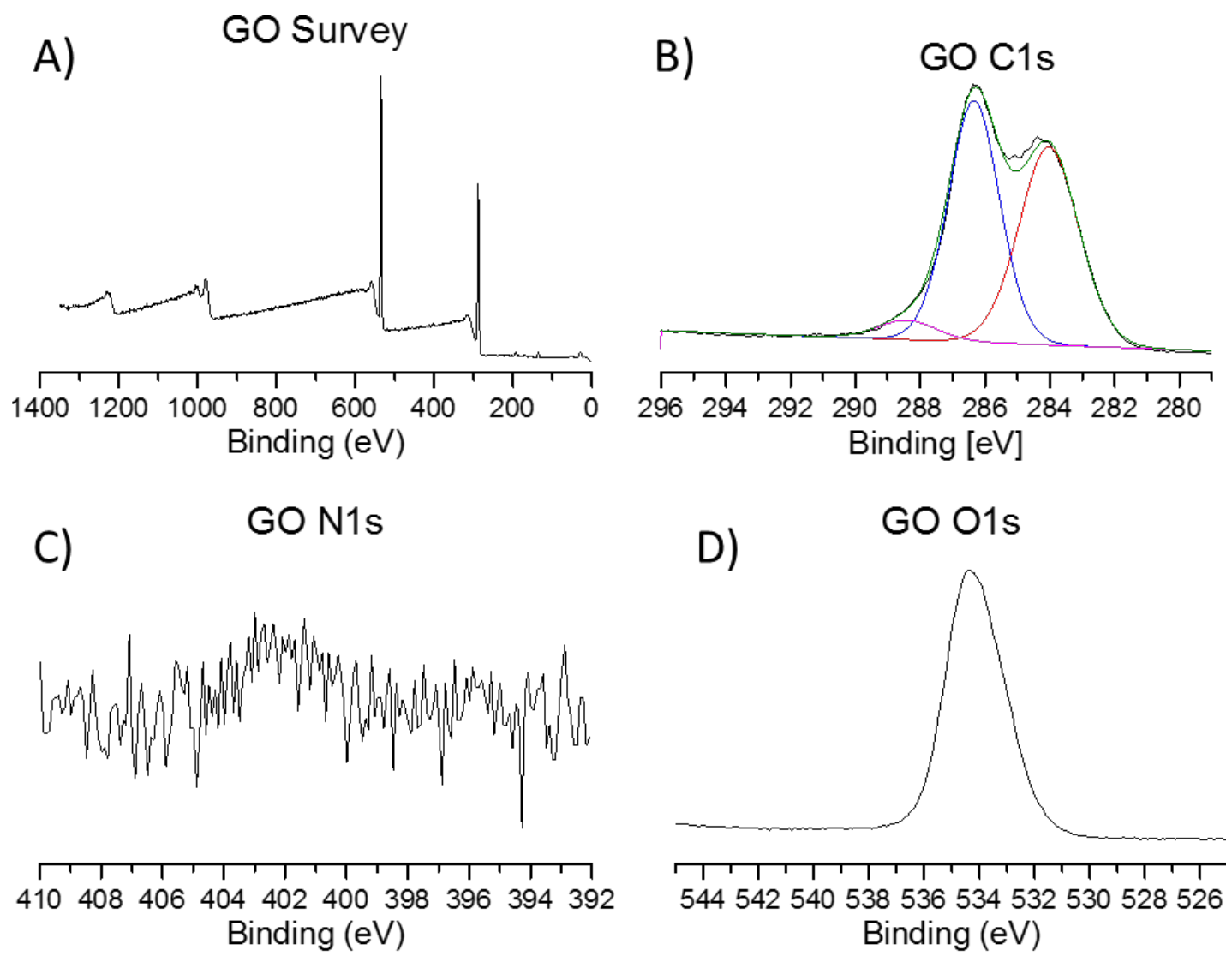

Figure S8. XPS of GO sheets. A) Elemental survey spectra showing only carbon and oxygen peaks. B) Carbon 1s spectra. When the spectra are fitted three distinct peaks can be deconvoluted from the data, sp ${ }^{3}$ C-C at $\approx 285 \mathrm{eV}$ (Red), C-O at $\approx 286 \mathrm{eV}$ (blue), and COO at $\approx 289 \mathrm{eV}$ (magenta). It is seen that the dominating peak is $\mathrm{C}-\mathrm{O}$ in the oxidized GO. C) Nitrogen 1s spectra; no significant nitrogen peak. D) Oxygen 1 s spectra with a single peak at $\approx 534 \mathrm{eV}$. 

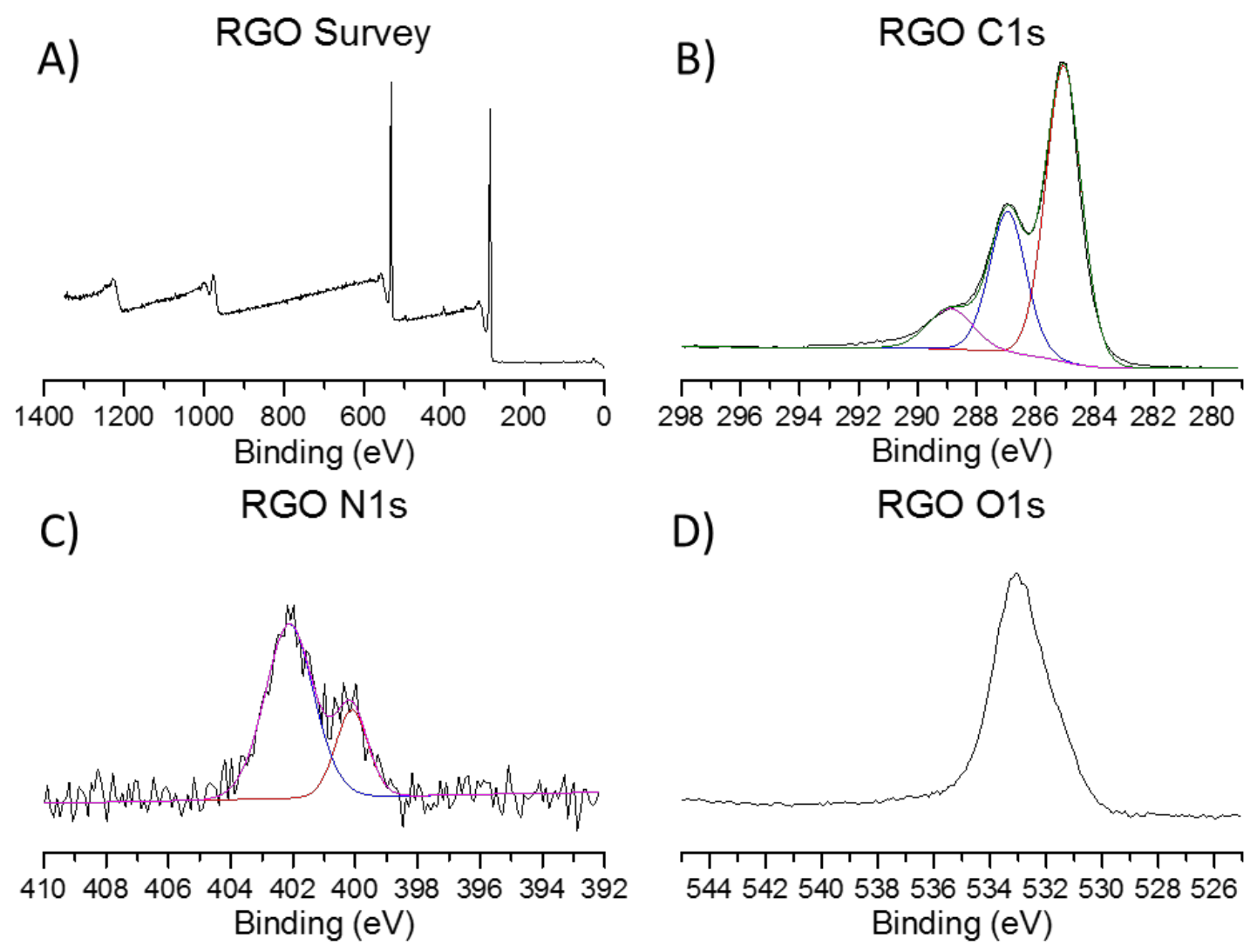

Figure S9. XPS of reference RGO sheets. A) Elemental survey spectra showing carbon and oxygen peaks and a small nitrogen peak. B) Carbon 1s spectra, when the spectra are fitted three distinct peaks can be deconvoluted from the data sp ${ }^{2} \mathrm{C}-\mathrm{C}$ at $\approx 284.8 \mathrm{eV}$ (Red), C-O at $\approx 286 \mathrm{eV}$ (blue), and $\mathrm{COO}$ at $\approx 289 \mathrm{eV}$ (magenta). It is seen that the dominating peak is $\mathrm{sp}^{2} \mathrm{C}-\mathrm{C}$ but C-O is still significant as a result of the mild reduction of GO. C) Nitrogen 1s spectra a small peak of nitrogen is found which is can be deconvoluted into two peaks one at $\approx 400 \mathrm{eV}$ and one at $\approx 402 \mathrm{eV}$. D) Oxygen $1 \mathrm{~s}$ spectra with a single peak at $\approx 533 \mathrm{eV}$. 

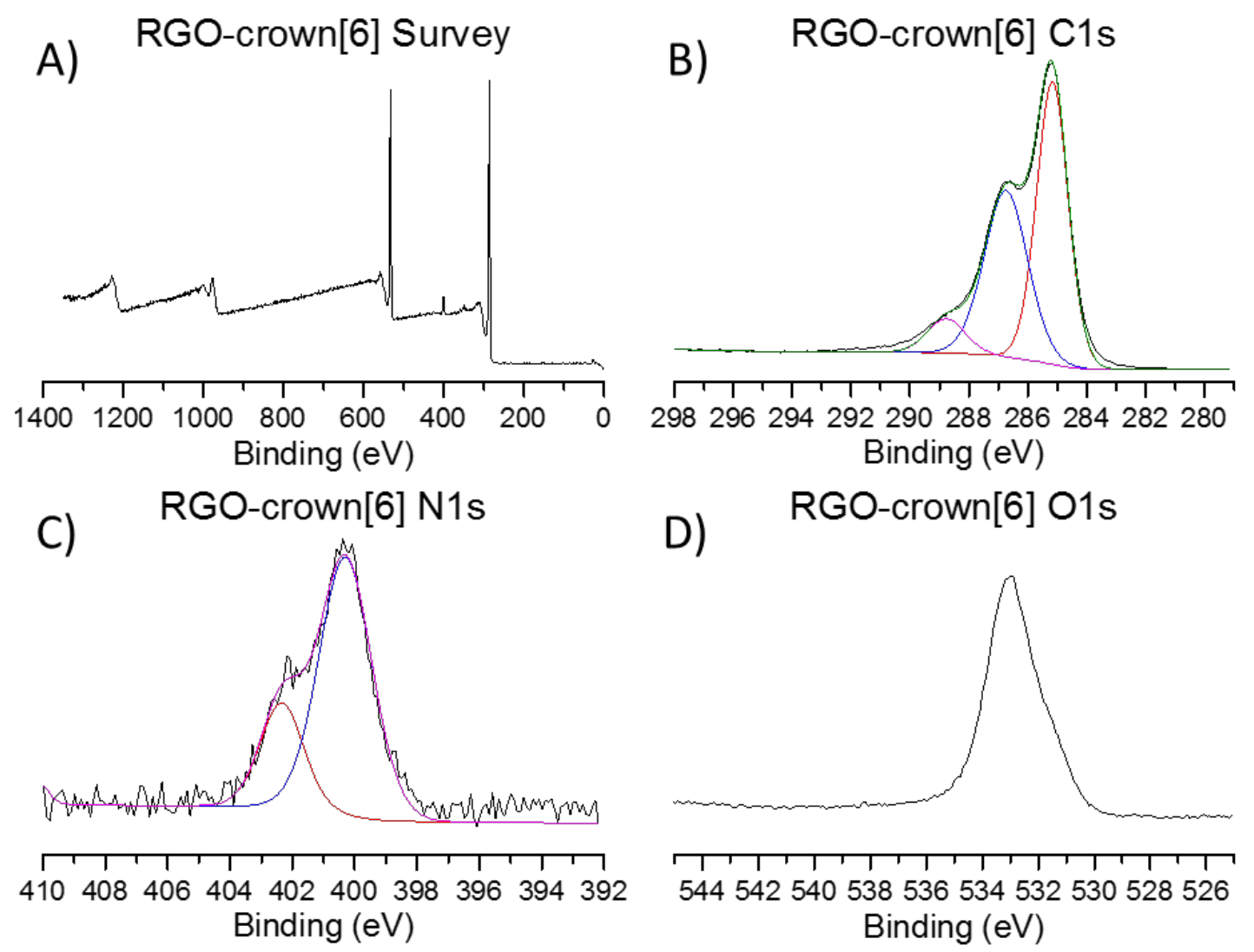

Figure S10. XPS of reference RGO sheets. A) Elemental survey spectra showing carbon, oxygen and nitrogen peaks. B) Carbon 1s spectra; when the spectra are fitted three distinct peaks can be deconvoluted from the data, SP ${ }^{2}$ C-C at $\approx 284.8 \mathrm{eV}$ (Red), C-O at $\approx 286 \mathrm{eV}$ (blue), and COO at $\approx 289$ $\mathrm{eV}$ (magenta). It is seen that the dominate peak is sp $\mathrm{s}^{2} \mathrm{C}$ but $\mathrm{C}-\mathrm{O}$ is still of significant as a result of the mild reduction of $\mathrm{GO}$; furthermore the ratio of $\mathrm{C}-\mathrm{C}$ to $\mathrm{C}-\mathrm{O}$ is lower than in the reference RGO due to the introduction of C-O from crown-ether. C) Nitrogen 1s spectra; a small peak of nitrogen is found which can be deconvoluted into two peaks, one at $\approx 400 \mathrm{eV}$ and one at $\approx 402 \mathrm{eV}$. D) Oxygen $1 \mathrm{~s}$ spectra with a single peak at $\approx 533 \mathrm{eV}$. 


\section{S5. Estimation of crown-ether coverage on RGO sheets}

The increased amount of nitrogen in RGO-crown compared to reference RGO is assumed to arise from the crown-ether moieties. Atomic percentage of each crown-ether moiety contains two nitrogen atoms $\left(\mathrm{C}_{14} \mathrm{O}_{7} \mathrm{~N}_{2}\right)$, i.e. $1.25 \%$. Carbon in $\mathrm{RGO}$ can be calculated as total carbon minus carbon introduced by crown-ether moiety,

$$
\text { i. e. } 75.1-(1.25 \cdot 14)=57.6 \% \text {. }
$$

A similar calculation for oxygen in RGO gives $21.5-(1.25 \cdot 7)=12.8 \%$.

The carbon to oxygen ratio in the RGO can then be calculated from these adjusted atomic percentages as $57.6 / 12.8=1: 4.5$

Likewise the carbon to crown-ether ratio can be calculated as $57.6 / 1.25=1: 46$

We can furthermore calculate the coverage of the theoretical surface area using the calculations by A. Peigney and associates ${ }^{2}$ of the surface area of a graphitic carbon 5.246 $\AA^{2}$. In their calculation this is the surface area of two carbon atoms but only one side i.e. the outside of a rolled-up graphene nanosheet as they used for nanotubes. Here we will use the same area as both sides of the RGO sheet. The area of RGO avalible for the 46 carbon atoms is thereby $241.3 \AA^{2}$.

To calculate the area of a crown-ether we assume that the crown ether molecule is circular and the diameter equal to the distance between opposing hydrogen atoms as determined by the crystal structure ${ }^{3}$ plus the diameter of a hydrogen atom total diameter $10.2 \AA^{2}$. This gives the resulting used area of $\left(\frac{10.2}{2}\right)^{2} \cdot \pi=81.7 \AA^{2}$

The coverage is thus estimated as $81.7 / 241.3=34 \%$ 


\section{S6. Electrochemical setup and measurements}

All electrochemical measurements was performed on am electrochemical workstation (CHI 760C, CH Instruments Inc., USA) with a Saturated calomel electrode (SCE) as a reference electrode in ambient atmosphere.

\section{Glassy carbon electrodes}

Prior to functionalization, glassy carbon electrodes were first polished using water based alumina slurry $(1 \mu \mathrm{m}, 0.3 \mu \mathrm{m}$ and $0.05 \mu \mathrm{m})$. Then, the hybrid material suspended in an aqueous solution $(1 \mathrm{mg} / \mathrm{mL}$ ) was drop-cast on the electrode surface, which was dried overnight before measurements in a $15 \mathrm{~mL}$ electrochemical cell.

\section{Screen-printed carbon electrodes}

Screen-printed carbon electrodes (SPCEs) from DroopSens (DS, mode number 150) were used. These electrodes contain a $4 \mathrm{~mm}$ diameter working electrode of carbon, a platinum counter electrode and a silver reference electrode. These electrodes were functionalized directly without further pretreatment (except for cleaning with ethanol) by drop casting functional material as an aqueous solution $(1 \mathrm{mg} / \mathrm{mL})$ on the electrode, which was dried overnight. When testing samples the potential of a $0.1 \mathrm{M} \mathrm{NaNO}_{3}$ was first measured, followed by real samples using an ideal sample volume of $50 \mu \mathrm{L}$.
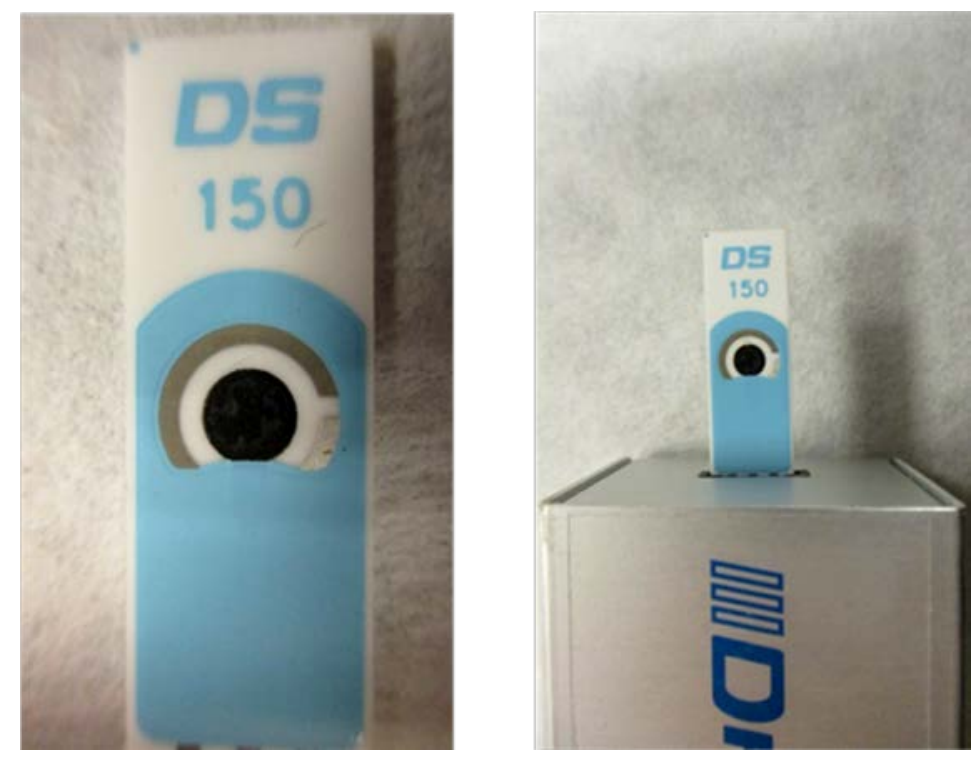

Figure S11. Photographs of a screen-printed carbon electrode loaded with RGO-Crown[6] (SPCE, left) and the measurement setup interface (right). 


\section{S7. Supporting references}

[1] Fulmer, G. R.; Miller, A. J. M.; Sherden, N. H.; Gottlieb, H. E.; Nudelman, A.; Stoltz, B. M.; Bercaw, J. E.; Goldberg, K. I.; Gan, R.; Apiezon, H. NMR Chemical Shifts of Trace Impurities: Common Laboratory Solvents, Organics, and Gases in Deuterated Solvents Relevant to the Organometallic Chemist. Organometallics 2010, 29, 2176-2179.

[2] Peigney, A.; Laurent, C.; Flahaut, E.; Bacsa, R. R.; Rousset, A. Specific Surface Area of Carbon Nanotubes and Bundles of Carbon Nanotubes. Carbon 2001, 39, 507514.

[3] Brennessel, W. W.; Ellis, J. E. Crystal Structure of (18-Crown-6)potassium(I) $[(1,2,3,4,5-\eta)$-cycloheptadienyl][(1,2,3-n)-cycloheptatrienyl]cobalt(I). Acta Crystallogr. Sect. E Crystallogr. Commun. 2015, 71, 291-295. 